\title{
Brazilian norms and effects of age and education on the Hayling and Trail Making Tests
}

\author{
Normas brasileiras e efeitos de idade e escolaridade no Teste Hayling e no \\ Teste de Trilhas
}

Nicolle Zimmermann, ${ }^{1}$ Caroline de Oliveira Cardoso, ${ }^{2}$ Christian Haag Kristensen, ${ }^{3}$ Rochele Paz Fonseca ${ }^{3}$

\begin{abstract}
Objectives: To describe normative data for the Hayling Test and the Trail Making Test (TMT) in a sample of Brazilian adults, and to investigate the effects of age and education on test performance.

Method: A total of 313 (TMT) and 364 (Hayling) individuals with age ranges of 19-39, 40-59, and 60-75 years, and with at least 5 years of formal education, participated in this study. The tests were administered as part of a large battery of a normative project. Individuals were evaluated individually in silent, ventilated rooms at a university clinic. Instrument protocols were scored by trained research assistants and double-checked to ensure data reliability.

Results: There were major effects of age on the TMT (Time $B$, Errors B, B-A) and on the Hayling Test (Errors B/15, B/45), and major effects of education on the TMT (Time $B$, Errors $B, B-A$ ) and on the Hayling Test (Time A, Errors B/15, B/45). Interaction effects were found in Time $B$ and $B-A$ for the Hayling Test and in Time A for the TMT.

Conclusions: Age and education were critical for performance on both verbal and non-verbal executive functions.

Keywords: Executive functions, age, education, Trail Making Test, Hayling Test.
\end{abstract}

\begin{abstract}
Resumo
Objetivos: Descrever dados normativos do Teste Hayling e do Teste de Trilhas em uma amostra de adultos brasileiros e investigar os efeitos de idade e escolaridade no desempenho das tarefas.

Método: Participaram deste estudo um total de 313 (TMT) e 364 (Hayling) indivíduos com idades nos intervalos de 19-39, 40-59 e 60-75 anos e com pelo menos 5 anos de escolaridade formal. Os testes foram administrados como parte de uma bateria maior de um projeto de normatização. Os indivíduos foram avaliados individualmente em salas silenciosas e ventiladas em uma clínica universitária. As pontuações dos protocolos foram realizadas por assistentes de pesquisa treinados e foram checadas duplamente para garantir a fidedignidade dos dados.

Resultados: Foram encontrados efeitos principais de idade no TMT (Tempo B, Erros B e Tempo B-A) e no Teste Hayling (Erros $B / 15$ e $B / 45$ ), e efeitos principais de educação no TMT (Tempo $B$, Erros B e Tempo B-A) e no Teste Hayling (Tempo A, Erros B/15 e $B / 45$ ). Foram encontrados efeitos de interação entre variáveis nos Tempos B e B-A do Teste Hayling e no Tempo A do TMT.

Conclusões: Idade e escolaridade foram fatores críticos para o desempenho em ambos os testes verbal e não-verbal de avaliação das funções executivas.

Descritores: Funções executivas, idade, escolaridade, Teste de Trilhas, Teste Hayling.
\end{abstract}

\footnotetext{
${ }^{1}$ Instituto Estadual do Cérebro Paulo Niemeyer, Serviço de Neuropsicologia, Centro de Epilepsia, Rio de Janeiro, RJ, Brazil. ${ }^{2}$ Faculdade de Psicologia, Universidade Feevale, Novo Hamburgo, RS, Brazil. ${ }^{3}$ Departamento de Psicologia, Pontifícia Universidade Católica do Rio Grande do Sul, Porto Alegre, RS, Brazil. Submitted Jan 10 2017, accepted for publication Apr 202017.

Suggested citation: Zimmermann N, Cardoso CO, Kristensen $\mathrm{CH}$, Fonseca RP. Brazilian norms and effects of age and education on the Hayling and Trail Making Tests. Trends Psychiatry Psychother. 2017;39(3):188-195. http://dx.doi.org/10.1590/2237-6089-2016-0082
} 


\section{Introduction}

Executive functions (EF) are critical for complex, goal-directed, adaptive behaviors, and they are related to important clinical and social behaviors throughout life. ${ }^{1}$ Current updated cognitive EF models consider as major components the working memory (central executive), cognitive flexibility, and inhibitory control. ${ }^{2}$ They are divided into subcomponents and also consider higher-order EF, such as planning, decision making, and fluid intelligence. EF are triggered when people need to accomplish tasks moving from their "automatic pilot" to a different way of thinking and acting. ${ }^{2}$

Neurological and psychiatric disorders are associated with EF dysfunctions, which lead to changes in the perspective of EF as frontal lobe-only functions, in spite of the evident special role of the frontal lobe. ${ }^{3}$ Some examples of EF problems are difficulties in recognizing changes and applying feedback, giving repetitive responses, planning and organizing tasks or events, reasoning, controlling impulses, and initiating behavior. ${ }^{4}$ The impacts of EF impairments on the individual's daily life, quality of life, and psychosocial adjustment have been matter of investigation. ${ }^{5}$ There is a consensus that the assessment of EF in clinical neuropsychology is essential for accurate diagnosis and intervention planning, as well as for follow-up of outcomes in different disorders. ${ }^{6}$

Several paradigms have been developed to assess different components of EF. Bipartite tasks are highlighted in the literature for allowing the transition from an automatic or less complex activity to a more controlled or more difficult and complex way of thinking. ${ }^{7}$ The Hayling Sentence Completion Test, ${ }^{8}$ or Hayling Test, is a verbal EF paradigm that requires patients to complete sentences with words that match them (Part A) and do not match them at all (Part B). In Part $A$, the Hayling Test evaluates verbal initiation, planning, processing speed, and syntactic-semantic linguistic process. In Part B, it evaluates components of inhibition, cognitive flexibility, and processing speed. Those components are closely associated to the lexicalsemantic system in the Hayling Test paradigm. ${ }^{9}$ The utility of the Hayling Test for clinical neuropsychology is evidenced in studies with neurological and psychiatric adult samples. ${ }^{10}$ Similarly, the Trail Making Test (TMT) assesses, in Part A, concentrated and focused visual attention and visual processing speed, and in Part $B$, alternated visual attention and cognitive flexibility. Also, qualitative analyses may provide evidence of inhibitory control functioning (for example, when a patient persists in connecting wrong sequences). ${ }^{11}$ The applicability of the TMT has been demonstrated in neurological adult samples, including people with mild cognitive impairment and dementia. ${ }^{12}$

The current study aims to present norms for the Hayling Test and the TMT for the Brazilian population. As far as we know, there are no adult normative studies employing the Hayling Test in a Brazilian sample, even though norms have been published for children. ${ }^{13,14}$ The adapted task for Brazilian Portuguese was published by Fonseca et al. ${ }^{15}$ With respect to the TMT, there are some studies published with adult samples from the Brazilian states of São Paulo ${ }^{16,17}$ and Paraná. ${ }^{18}$

\section{Methods}

\section{Participants}

In the current study, community volunteers with ages ranging from 19 to 75 (mean $=40.41$; standard deviation $=17.00$ ) were recruited by convenience at universities, companies, and centers for activities (for example, painting or sports groups), or by word-ofmouth in the city of Porto Alegre, Brazil. For inclusion in the study, participants had to be native Brazilian speakers and have completed at least 5 years of formal education. A self-reported history of psychiatric or neurological disorder, uncorrected visual or hearing problems, abuse of cigarettes, illegal drugs, alcohol, or psychoactive medications were considered exclusion criteria. In addition, the Mini Mental State Examination ${ }^{19}$ was applied to individuals who were $\geq 40$ years old, in order to exclude abnormal cognitive performance. Furthermore, all participants had to score $<10$ on the Geriatric Depression Scale (GDS-15), ${ }^{20}$ a 15 -item scale that assesses depressive symptoms. A questionnaire from the Brazilian Association of Research Companies (Associação Brasileira de Empresas de Pesquisa, ABEP) was used to obtain the participants' socioeconomic classification.

After a complete assessment of inclusion and exclusion criteria, 418 individuals performed the TMT, and 388 the Hayling Test. After a qualitative analysis of data, 46 individuals were excluded from the TMT sample, and 24 from the Hayling Test sample (due to administration errors, absence of sociodemographic or clinical data, lack of task comprehension or inability to minimally perform the task - which was the case of poorly educated individuals who did not have the alphabet as an automatic language skill). As a result, the TMT sample comprised 372 individuals, and the Hayling Test sample, 364. Table 1 presents sociodemographic and clinical data from both samples. Participants signed an informed consent form that was approved by the ethics committee of our institution (protocol no. 09/04908). 


\section{Instruments}

The TMT and the Hayling Test were administered as part of a large battery of a normative project, comprised of the following tests: Digit Span (administration time: $\sim 8$ minutes), Stroop Color and Word Test (administration time: $~ 7$ minutes), and Modified Wisconsin Card Sorting Test (administration time: $\sim 15$ minutes)..$^{21}$ Individuals were evaluated individually in silent, ventilated rooms at a university clinic. The administration order of the test battery was counterbalanced among participants, and oral and visual paradigms were administered alternately. Instrument protocols were scored by trained research assistants and double-checked to ensure data reliability. Test instructions and scoring norms are currently being prepared for publication by the authors. Briefly, the authors suggest that the test be applied in individuals with enough educational experience to appropriately understand and perform the tasks. For example, individuals who are not aware of alphabetical order will not present valid responses on TMT Part B.

The TMT $^{22}$ assesses visual search strategy and speed, praxis processing speed, visual attention, and cognitive flexibility. In Part A, individuals were required to connect numbers randomly distributed in an A4 paper sheet, as fast as they could. After that, in Part $B$, individuals had to connect alternating numbers and letters (for example: 1-A, 2-B, 3-C), also as fast as possible. In both parts, the maximum time allowed was 5 minutes. Time, accuracy (maximum of 24) and errors were considered for scoring. Adaptation procedures and instructions for this Brazilian version are currently being prepared for publication by the authors. Total administration time was around 10 minutes.

The Hayling Sentence Completion Test ${ }^{15,23}$ is a verbal instrument developed to assess initiation and inhibition of verbal stimuli, based on the Supervisory Attentional System model. The task requires the subject to complete sentences in Parts A and B. In Part $A$, individuals had to complete general sentences with words that would fit properly; in Part B, they had to complete other sentences with random unrelated words. Participants were required to evoke the words as fast as they could. Each part comprised 15 items. Error scores and total time to complete each item were calculated separately for each task part. Particularly, in Part B, a qualitative-quantitative error score was proposed: each answer type received different scores. The higher the score, the lower the qualitative performance. Fonseca et al. ${ }^{15}$ provide complete data on adaptation, rapport and scoring procedures. Total administration time was around 10 minutes.

\section{Data analysis}

After verifying data normality and sample homogeneity (Kolmogorov-Smirnov and Levene tests), instrument scores were analyzed using univariate analysis of variance for age, years of study (education), and sex variables. Significant results were followed by Bonferroni post-hoc procedure. Means and standard deviations were provided by descriptive statistical methods. All analyses were performed using the Statistical Package for the Social Sciences (SPSS), with significance set at $p \leq 0.05$.

\section{Results}

Descriptive statistics (means and standard deviations) obtained in the TMT and the Hayling Test are shown in Tables 2 and 3, respectively. Age and education effects analyses are presented in Table 4.

Sex did not have any effect on performance in both tasks. In the TMT, results were as follows: Time $A$, $\mathrm{F}=1.514, \mathrm{p}=0.219$; Errors $\mathrm{A}, \mathrm{F}=1.354, \mathrm{p}=0.245$; Time $B, F=0.974, p=0.331$; Errors $B, F=2.225, p=0.134$; Time $B-A, F=2.490, p=0.115$. A similar pattern regarding sex was found in the Hayling Test: Time $A, F=0.000$, $p=0.991$; Errors $A, F=0.287, p=0.592$; Time $B, F=1.824$, $p=0.178$; Errors $B / 15, F=0.011, p=0.917$; Errors $B / 45$, $F=0.095, p=0.758$; Time $B-A, F=2.038, p=0.154$.

According to Table 4, the effects of age and education were similar for Time B, Errors B, and Time B-A in the TMT. Conversely, Hayling Test analyses indicated that the education effect was slightly more frequent than age effects. Interaction effects were found in the TMT for Time A (Figure 1), and in the Hayling Test for Time B (Figure 2) and Time B-A (Figure 3).

\section{Discussion}

In this article, we aimed to investigate age and education effects on TMT and Hayling Test performance in a healthy Brazilian sample, searching for reference normative data for Brazilian Portuguese. The main characteristics of the sample were age range from 19 to 75 years and 5 or more years of formal education. There were major effects of age on the TMT (Time B, Errors $B$, Time $B-A$, and Time $B / A$ ) and on the Hayling Test (Errors $B / 15$ and $B / 45)$, and also major effects of education on the TMT (Time B, Errors B, Time B-A, and Time B/A) and on the Hayling Test (Time $A$, Errors $B / 15$ and $B / 45$ ). Interaction effects were found on Time $B$ and Time $B-A$ for the Hayling Test and on Time A for the TMT. 

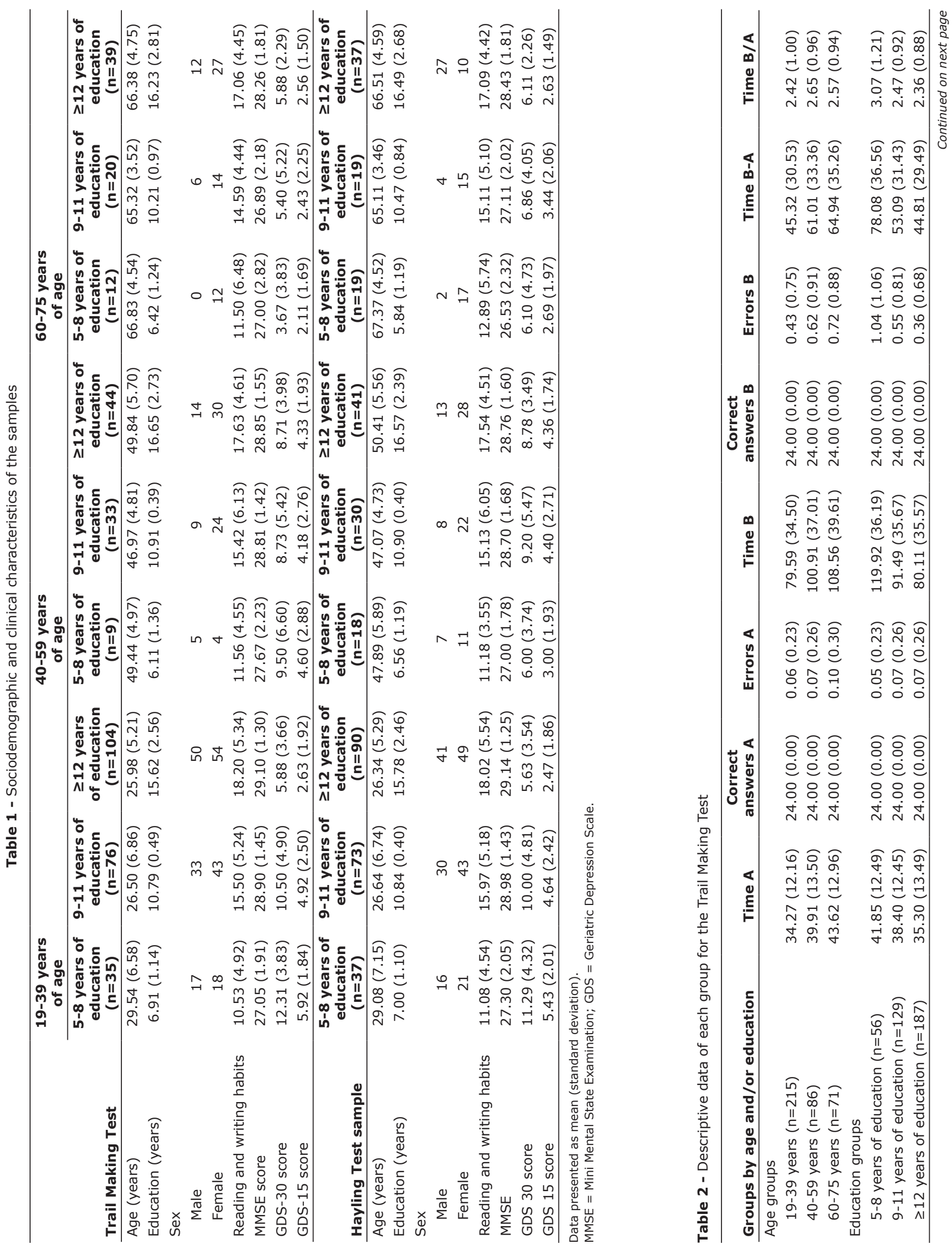


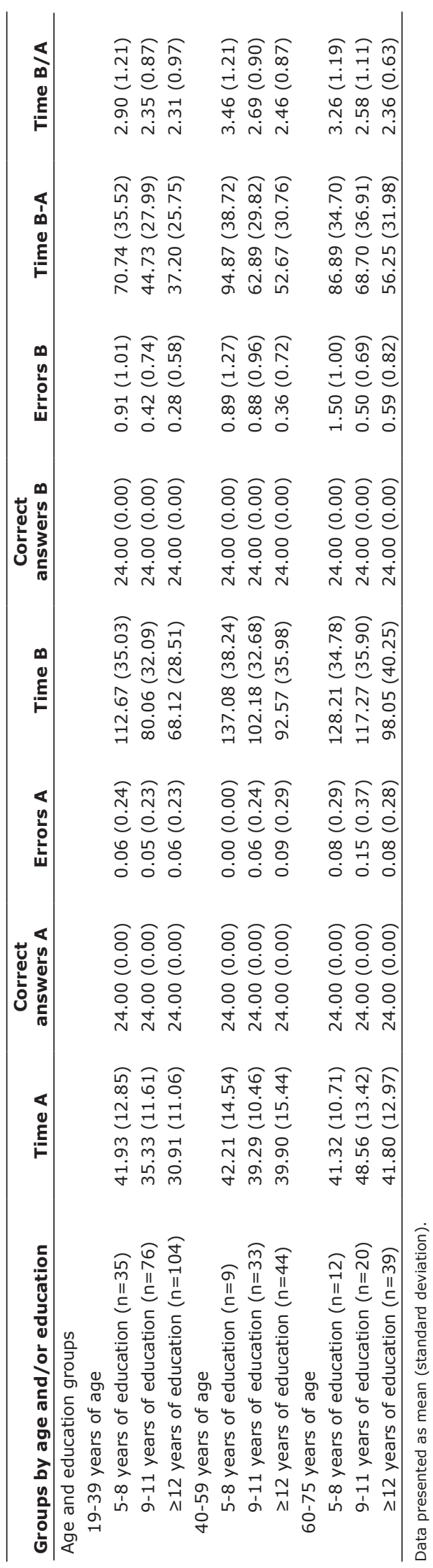

192 - Trends Psychiatry Psychother. 2017;39(3)

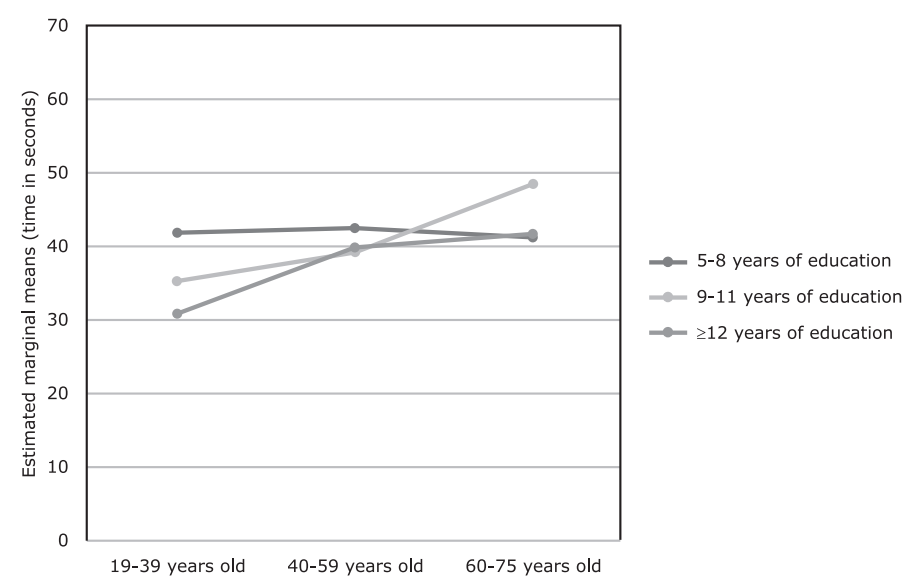

Figure 1 - Interaction effect between age and education in the Trail Making Test - Time A.

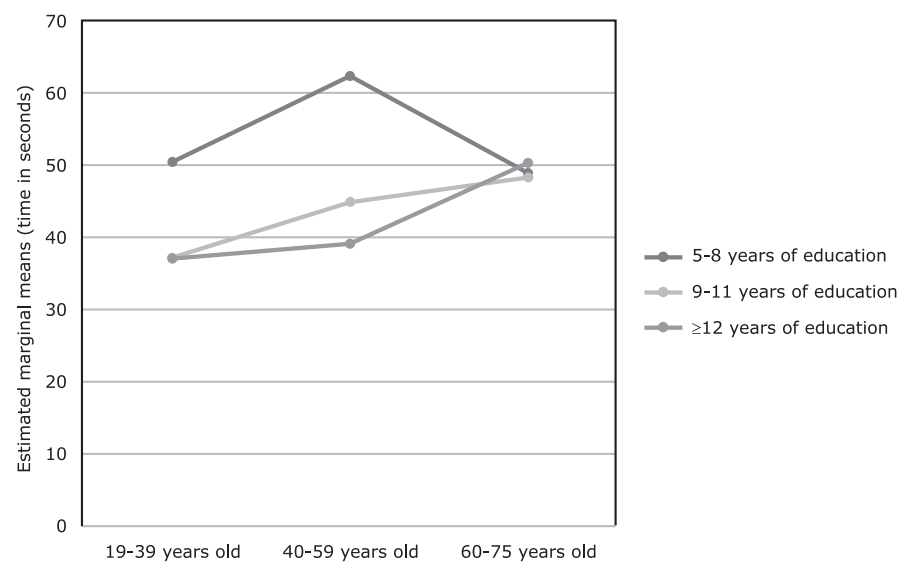

Figure 2 - Interaction effect between age and education in the Hayling Test - Time B.

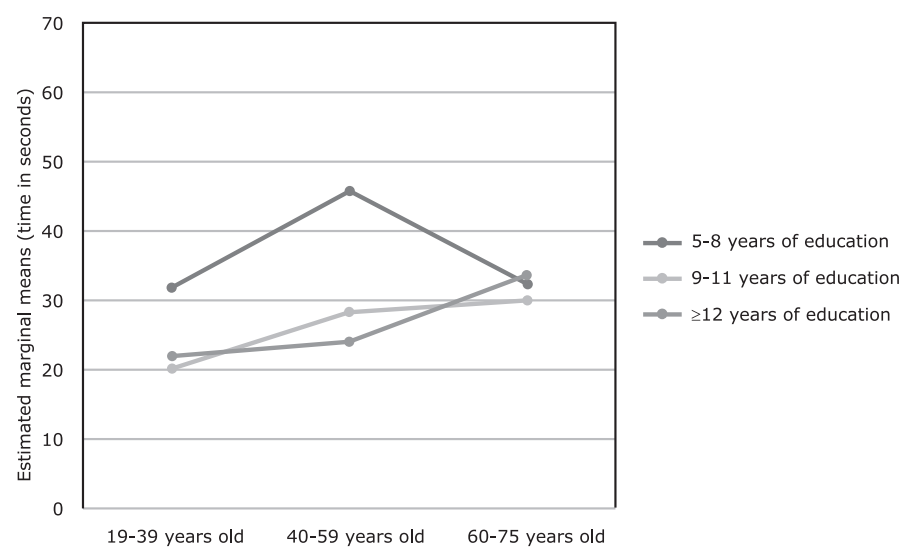

Figure 3 - Interaction effect between age and education groups in the Hayling Test - Time B-A. 
Table 3 - Descriptive data of each group for the Hayling Test

\begin{tabular}{|c|c|c|c|c|c|c|}
\hline Groups by age and/or education & Time A & Errors A & Time B & Errors B/15 & Errors B/45 & Time B-A \\
\hline \multicolumn{7}{|l|}{ Age groups } \\
\hline $19-39$ years $(n=200)$ & $16.22(6.08)$ & $0.20(0.43)$ & $39.49(20.18)$ & $2.44(2.02)$ & $10.26(6.66)$ & $23.27(18.43)$ \\
\hline $40-59$ years $(n=89)$ & $15.73(6.07)$ & $0.17(0.41)$ & $45.76(21.43)$ & $2.62(2.23)$ & $11.53(6.99)$ & $30.03(20.72)$ \\
\hline $60-75$ years $(n=75)$ & $17.02(4.91)$ & $0.24(0.49)$ & $49.49(17.36)$ & $3.65(2.28)$ & $13.91(6.79)$ & $32.46(16.93)$ \\
\hline \multicolumn{7}{|l|}{ Education groups } \\
\hline $5-8$ years of education $(n=74)$ & $17.56(5.58)$ & $0.19(0.39)$ & $52.95(19.21)$ & $4.01(2.28)$ & $15.28(6.60)$ & $35.39(18.97)$ \\
\hline $9-11$ years of education $(n=122)$ & $16.92(7.19)$ & $0.25(0.47)$ & $40.80(19.18)$ & $2.39(1.93)$ & $9.75(6.53)$ & $23.88(17.24)$ \\
\hline$\geq 12$ years of education $(n=168)$ & $15.22(4.63)$ & $0.17(0.42)$ & $40.39(20.40)$ & $2.42(2.11)$ & $10.71(6.66)$ & $25.18(19.46)$ \\
\hline \multicolumn{7}{|l|}{ Age and education groups } \\
\hline \multicolumn{7}{|l|}{$19-39$ years of age } \\
\hline $5-8$ years of education $(n=37)$ & $18.49(4.88)$ & $0.24(0.43)$ & $50.40(17.86)$ & $3.68(1.78)$ & $13.78(5.24)$ & $31.91(17.29)$ \\
\hline $9-11$ years of education $(n=73)$ & $16.83(7.74)$ & $0.26(0.50)$ & $37.16(18.44)$ & $2.12(1.91)$ & $8.82(6.64)$ & $20.33(15.50)$ \\
\hline$\geq 12$ years of education $(n=90)$ & $14.79(4.48)$ & $0.13(0.34)$ & $36.89(21.11)$ & $2.19(2.03)$ & $9.97(6.74)$ & $22.10(20.13)$ \\
\hline \multicolumn{7}{|l|}{$40-59$ years of age } \\
\hline $5-8$ years of education $(n=18)$ & $16.61(7.30)$ & $0.17(0.38)$ & $62.38(20.18)$ & $4.56(2.66)$ & $17.17(7.92)$ & $45.77(21.20)$ \\
\hline $9-11$ years of education $(n=30)$ & $16.36(7.05)$ & $0.10(0.31)$ & $44.88(21.50)$ & $2.27(1.80)$ & $9.60(6.10)$ & $28.52(20.48)$ \\
\hline$\geq 12$ years of education $(n=41)$ & $14.88(4.58)$ & $0.22(0.47)$ & $39.11(18.22)$ & $2.02(1.86)$ & $10.46(5.97)$ & $24.23(17.37)$ \\
\hline \multicolumn{7}{|l|}{$60-75$ years of age } \\
\hline $5-8$ years of education $(n=19)$ & $16.65(4.96)$ & $0.11(0.32)$ & $48.98(18.85)$ & $4.16(2.73)$ & $16.42(7.27)$ & $32.33(17.16)$ \\
\hline $9-11$ years of education $(n=19)$ & $18.14(5.00)$ & $0.42(0.51)$ & $48.33(15.06)$ & $3.63(1.77)$ & $13.58(5.55)$ & $30.19(15.24)$ \\
\hline$\geq 12$ years of education $(n=37)$ & $16.64(4.89)$ & $0.22(0.53)$ & $50.35(18.07)$ & $3.41(2.28)$ & $12.78(6.95)$ & $33.70(17.92)$ \\
\hline
\end{tabular}

Data presented as mean (standard deviation).

Table 4 - Main effects, interactions, and post-hoc Bonferroni results

\begin{tabular}{|c|c|c|c|c|c|c|c|c|c|c|c|}
\hline & \multicolumn{3}{|c|}{ Age } & \multicolumn{3}{|c|}{ Education } & \multicolumn{3}{|c|}{ Interaction } & \multicolumn{2}{|c|}{ Post-hoc } \\
\hline & $\mathbf{F}$ & $\boldsymbol{p}$ & $\begin{array}{c}\text { Partial } \\
\eta^{2}\end{array}$ & $\mathbf{F}$ & $p$ & $\begin{array}{c}\text { Partial } \\
\eta^{2}\end{array}$ & $\mathbf{F}$ & $p$ & $\begin{array}{c}\text { Partial } \\
n^{2}\end{array}$ & Age & Education \\
\hline \multicolumn{12}{|c|}{ Trail Making Test } \\
\hline Time A & 9.600 & $<0.001$ & 0.050 & 3.430 & 0.036 & 0.019 & 2.791 & 0.026 & 0.030 & \multicolumn{2}{|r|}{ * } \\
\hline Errors A & 0.862 & 0.423 & 0.005 & 0.375 & 0.688 & 0.002 & 0.506 & 0.731 & 0.006 & & \\
\hline Time B & 22.028 & $<0.001$ & 0.101 & 23.592 & $<0.001$ & 0.115 & 0.692 & 0.598 & 0.008 & $\begin{array}{l}19-39<40-59 \\
19-39<60-75\end{array}$ & $\begin{array}{c}5-8>9-11 \\
5-8>12 \text { or more } \\
9-11>12 \text { or more }\end{array}$ \\
\hline Errors B & 4.046 & 0.018 & 0.022 & 12.696 & $<0.001$ & 0.065 & 2.016 & 0.092 & 0.022 & $19-39<60-75$ & $\begin{array}{c}5-8>9-11 \\
5-8>12 \text { or more }\end{array}$ \\
\hline Time B-A & 14.281 & $<0.001$ & 0.073 & 22.477 & $<0.001$ & 0.110 & 0.263 & 0.902 & 0.003 & $\begin{array}{l}19-39<40-59 \\
19-39<60-75\end{array}$ & $\begin{array}{c}5-8>9-11 \\
5-8>12 \text { or more } \\
9-11>12 \text { or more }\end{array}$ \\
\hline Time B/A & 3.234 & 0.041 & 0.018 & 12.207 & $<0.001$ & 0.063 & 0.418 & 0.795 & 0.005 & NS & $\begin{array}{c}5-8>9-11 \\
5-8>12 \text { or more }\end{array}$ \\
\hline \multicolumn{12}{|l|}{ Hayling Test } \\
\hline Time A & 0.828 & 0.438 & 0.005 & 3.379 & 0.035 & 0.019 & 0.940 & 0.441 & 0.010 & & NS \\
\hline Errors A & 0.743 & 0.477 & 0.004 & 1.030 & 0.358 & 0.006 & 2.070 & 0.084 & 0.023 & & \\
\hline Time B & 6.074 & 0.003 & 0.033 & 9.052 & $<0.001$ & 0.049 & 2.714 & 0.030 & 0.030 & & * \\
\hline Errors B/15 & 6.715 & 0.001 & 0.036 & 14.862 & $<0.001$ & 0.077 & 1.420 & 0.227 & 0.016 & $19-39<60-75$ & $\begin{array}{c}5-8>9-11 \\
5-8>12 \text { or more }\end{array}$ \\
\hline Errors B/45 & 6.941 & 0.001 & 0.038 & 14.664 & $<0.001$ & 0.076 & 0.852 & 0.493 & 0.010 & $19-39<60-75$ & $\begin{array}{c}5-8>9-11 \\
5-8>12 \text { or more }\end{array}$ \\
\hline Time B-A & 7.219 & 0.001 & 0.039 & 8.059 & $<0.001$ & 0.043 & 2.574 & 0.038 & 0.028 & & $*$ \\
\hline
\end{tabular}

NS $=$ non-significant differences.

Correct answers A and B from TMT did not present standard deviation values, therefore inferential analyses are not available.

* See Figures 1, 2, and 3 for interpretation of interactions among groups.

Bold font indicates significant results $(p \leq 0.05)$. 
With regards to the age effect on the Hayling Test, a previous study from Borella et al., ${ }^{24}$ with a sample from Switzerland, found that older age decreases the inhibition capacity required Part B. In the same study, this was observed with Errors, but not with Time. Those authors also failed to find effects of age on any other task variable. Another study assessing a Canadian and Belgian sample ${ }^{7}$ found the opposite, i.e., age effects were observed on Time B, but not on Errors B. Yet another study found age effects on Time $B$ and on Errors $B,{ }^{25}$ but not on Time $A$. Our hypothesis for the unexpected lack of effects of age on Time ${ }^{26}$ variables in the Hayling Test is that the measurement of time in a relatively large interval (60 seconds) caused important interindividual variability. In spite of not using the same method as Borella et al., ${ }^{24}$ but rather the same method as Belleville et al.,7 for time measurement, age effect may have had less impact on time measurement in our study for cultural reasons. A previous study showed that different cultures may present different performances on timed measures, but not in other types of measures, such as errors or accuracy. ${ }^{27}$ An Argentinian study by Abusamra et al. demonstrated education effects on Time $A$ and $B$ and on Errors of Part B. ${ }^{28}$

The influence of age on TMT variables has been largely reported. Most studies found the same effects (or correlations) on Time $B,{ }^{17,29}$ Errors B, and Errors B-A. ${ }^{30}$ Some research studies also found an effect of age on Time A. ${ }^{17,29}$ Our results indicate that age effects may be found in conditions with increased executive demands, such as in Part B of the task. The effect of education has also been reported in previous studies on the TMT A and B. ${ }^{17,29}$ These variable results may be attributed to differences in groups' age ranges, task application methods, and cultural aspects that were not analyzed in the present study.

When comparing the effects of both age and education on the TMT and Hayling Test in Part A, the TMT showed interaction effects (education had less impact on groups with age ranges 40-59 and 60-75 years), while in the Hayling Test only education had an effect on the first part. The variable Errors of Part A did not show any effect of age or education in any task, probably because the occurrence of errors in an automatic paradigm is uncommon regardless of age range or education level. Most studies do not present norms or analyses of these variables; however, we strongly believe that the analysis of errors may be an important feature for the appropriate diagnosis of dysexecutive symptoms. ${ }^{30}$ In Part B, the TMT showed major effects of age and education, while the Hayling Test presented interaction on time of execution (the 60-75-year old group did not present education effects regardless of education group; the 19-39-year old group did not present differences between the 5-8 and 9-11 years of education groups). Regarding the occurrence of errors in Part $B$, both tasks presented effects of age and education, which suggests that verbal and non-verbal EF tasks are affected by these factors. ${ }^{31}$ The Hayling formulae $B-A$ presented similar interaction effects than those obtained for Time B.

Observing the effects of age and education on neuropsychological assessment results is critical for valid clinical interpretation, since it may prevent falsenegative and false-positive results. Therefore, these two tasks can be considered complementary to assess dissociations and discrepancies among predominant verbal and non-verbal executive processing, being applicable mainly to patients with at least 5 years of education. Limitations of the present study include the recruitment method, exclusion of clinical symptoms or diagnosis by self-report, exclusion of individuals a posteriori because of administration errors or missing sociodemographic or clinical data, limited sample size and the large amplitude of educational level groups. Even though the main aim of this paper was to verify age and educational differences, both variables may be treated or studied as continuous factors in future studies. We also suggest that future studies increase sample size and include other relevant factors associated with education, such as frequency of reading and writing habits and quality of education. Also, future studies are warranted to investigate sensitivity and specificity of these versions of the TMT and the Hayling Test in different Brazilian clinical populations.

\section{Acknowledgments}

This study received financial support from Conselho Nacional de Desenvolvimento Científico e Tecnológico (CNPq). We would like to thank Gigiane Gindri, Camila de Oliveira, Francéia Lietdke, and Vinícius Dornelles for their hard work in collecting part of the data for this study. In addition, we are grateful to CNPq for providing the Edital Humanas 2008-2009 and also the scholarships for graduate students.

\section{Disclosure}

No conflicts of interest declared concerning the publication of this article. 


\section{References}

1. Miyake A, Friedman NP. The nature and organization of individual differences in executive functions: four general conclusions. Curr Dir Psychol Sci. 2012;21:8-14.

2. DiamondA. Executivefunctions. AnnuRevPsychol. 2013;64:135-68.

3. Castellanos NP, Leyva I, Buldú JM, Bajo R, Paúl N, Cuesta P, et al. Principles of recovery from traumatic brain injury: reorganization of functional networks. Neuroimage. 2011;55:1189-99.

4. Shanahan L, Mcallister L, Curtin M. The Party Planning Task: A useful tool in the functional assessment of planning skills in adolescents with TBI. Brain Inj. 2011;25:1080-90.

5. Torralva T, Strejilevich S, Gleichgerrcht E, Roca M, Martino D, Cetkovich $M$, et al. Deficits in tasks of executive functioning that mimic real-life scenarios in bipolar disorder. Bipolar Disord. 2012;14:118-25.

6. Salomone S, Fleming GR, Bramham J, OConnell RG, Robertson IH. Neuropsychological deficits in adult ADHD: evidence for differential attentional impairments, deficient executive functions, and high self-reported functional impairments. J Atten Disord. 2016 Jan 14. pii: 1087054715623045. [Epub ahead of print]

7. Belleville S, Rouleau N, Van der Linden M. Use of the Hayling task to measure inhibition of prepotent responses in normal aging and Alzheimer's disease. Brain Cogn. 2006;62:113-9.

8. Burgess PW, Shallice T. The Hayling and Brixton Tests. Thurston: Thames Valley Test Company; 1997.

9. Castner JE, Copland D A, Silburn P A, Coyne T], Sinclair F, Chenery $\mathrm{HJ}$. Lexical-semantic inhibitory mechanisms in Parkinson's disease as a function of subthalamic stimulation. Neuropsychologia. 2007; 45:3167-77.

10. Joshua $N$, Gogos A, Rossell $S$. Executive functioning in schizophrenia: a thorough examination of performance on the Hayling Sentence Completion Test compared to psychiatric and non-psychiatric controls. Schizophr Res. 2009;114:84-90.

11. Stuss DT, Bisschop SM, Alexander MP, Levine B, Katz D, Izukawa D. The trail making test: A study in focal lesion patients. Psychol Assess. 2001:13:230-9.

12. Ashendorf L, Jefferson AL, O'Connor MK, Chaisson C, Green RC, Stern RA. Trail Making Test errors in normal aging, mild cognitive impairment, and dementia. Arch Clin Neuropsychol. 2008;23:12937.

13. Siqueira $L$ de $S$, Gonçalves HA, Hübner LC, Fonseca RP. Development of the Brazilian version of the Child Hayling Test. Trends Psychiatry Psychother. 2016;38:164-74.

14. Siqueira LS, Gonçalves HA, Fonseca FP, Cargnin C, Fonseca RP. Teste Hayling Infantil: aplicação, registro, pontuação e dados normativos. In: Fonseca RP, Prando ML, Zimmermann N. Tarefas para avaliação neuropsicológica: avaliação de linguagem e funções executivas em crianças. São Paulo: Memnon; 2016. p. 66-86.

15. Fonseca RP, Oliveira C, Gindri G, Zimmermann N, Reppold C. Teste Hayling: um instrumento de avaliação de componentes das funções executivas. In: Hutz C, ed. Avaliação psicológica e neuropsicológica de crianças e adolescentes. São Paulo: Casa do Psicólogo; 2010. p. 337-64.

16. Yassuda S, Diniz BSO, Flaks MK, Viola LF, Pereira FS. Neuropsychological profile of Brazilian older adults with heterogeneous educational backgrounds. Arch Clin Neuropsychol. 2009;24:71-9.

17. Campanholo KR, Romão MA, Machado MD, Serrao VT, Coutinho DG, Benute GR, et al. Performance of an adult Brazilian sample on the Trail Making Test and Stroop Test. Dement Neuropsychol. 2014;8:26-31.

18. Hamdan A, Hamdan EM. Effect of age and education level on the Trail Making Test in the Brazilian healthy sample. Psychol Neurosci. 2009;2:199-203.

19. Chaves ML, Izquierdo I. Differential diagnosis between dementia and depression: a study of efficiency increment. Acta Neurol Scand. 1992;11:412-29.

20. Almeida $O P$, Almeida SA. Confiabilidade da versão brasileira da Escala de Depressão em Geriatria (GDS) versão reduzida. Arq Neuropsiquiatr. 1999;57:421-6.

21. Zimmermann N, Cardoso CDO, Trentini CM, Grassi-Oliveira R, Fonseca RP. Brazilian preliminary norms and investigation of age and education effects on the Modified Wisconsin Card Sorting Test, Stroop Color and Word test and Digit Span test in adults. Dement Neuropsychol. 2015;9:120-7.

22. Reitan RM, Wolfson D. The Halstead-Reitan Neuropsychology Battery: theory and clinical interpretation. Tucson: Neuropsychology Press; 1993.

23. Burgess PW, Shallice T. Response suppression, initiation and strategy use following frontal lobe lesions. Neuropsychologia. 1996;34:263-72.

24. Borella E, Ludwig C, Fagot D, De Ribaupierre A. The effect of age and individual differences in attentional control: a sample case using the Hayling test. Arch Gerontol Geriatr. 2011;53:e75-80.

25. Andrés $P$, Van der Linden $M$. Age-related differences in supervisory attentional system functions. J Gerontol B Psychol Sci Soc Sci. 2000;55:P373-80.

26. Salthouse TA. Structural models of the relations between age and measures of cognitive functioning. Intelligence. 2001;29:93115 .

27. Agranovich A V , Puente AE. Do Russian and American normal adults perform similarly on neuropsychological tests? Preliminary findings on the relationship between culture and test performance. Arch Clin Neuropsychol. 2007;22:273-82.

28. Abusamra $V$, Miranda MA, Ferreres A. Evaluación de la iniciación e inhibición verbal en español. Adaptación y normas del test de Hayling. Rev Argent Neuropsicol. 2007;9:19-32.

29. Bezdicek O, Motak L, Axelrod BN, Preiss M, Nikolai T, Vyhnalek M, et al. Czech version of the Trail Making Test: normative data and clinical utility. Arch Clin Neuropsychol. 2012;27:906-14.

30. Salthouse T A. What cognitive abilities are involved in trail-making performance? Intelligence. 2011;39:222-32.

31. Rosselli M, Ardila A. The impact of culture and education on nonverbal neuropsychological measurements: A critical review. Brain Cogn. 2003;52:326-33.

\section{Correspondence:}

Nicolle Zimmermann

Instituto Estadual do Cérebro Paulo Niemeyer, Serviço de Neuropsicologia, Centro de Epilepsia

Rua do Rezende, 156, Centro

20230-024 - Rio de Janeiro, RJ - Brazil

E-mail: nicolle.zimmermann@gmail.com 